
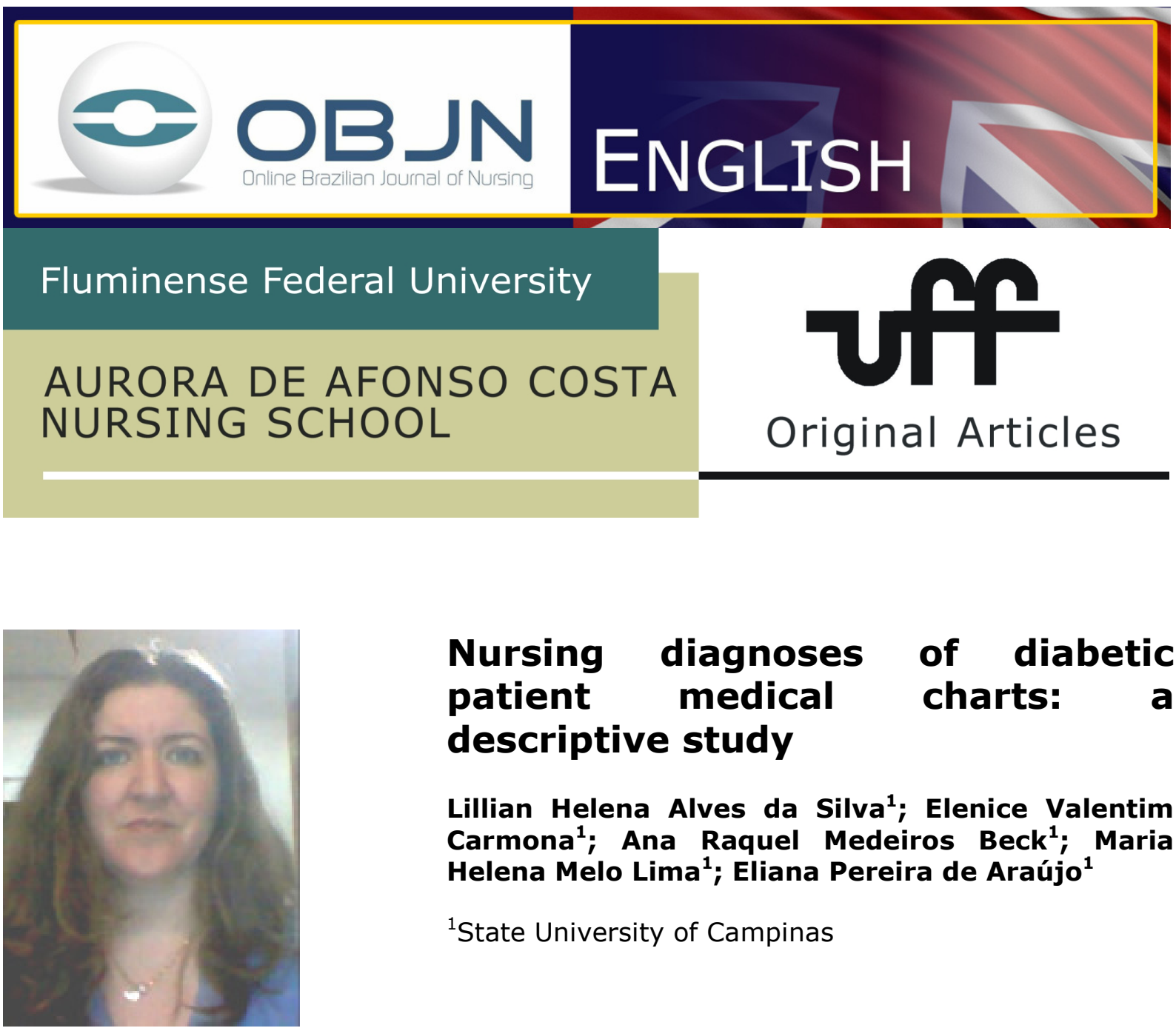

\title{
Nursing diagnoses of diabetic patient medical charts: a descriptive study
}

\section{Lillian Helena Alves da Silva ${ }^{1}$; Elenice Valentim Carmona ; Ana Raquel Medeiros Beck ${ }^{1}$; Maria Helena Melo Lima ${ }^{1}$; Eliana Pereira de Araújo ${ }^{1}$}

${ }^{1}$ State University of Campinas

\section{ABSTRACT}

Aim: identifying taxonomy II nursing diagnoses from the North American Nursing Diagnoses Association International using nursing records associated with outpatient diabetic

treatment.

Method: a descriptive and retrospective study. Data obtained from 35 patients' medical charts, using a tool devised by the authors and analyzed using relative and absolute frequencies.

Result: from eight diagnoses, three of the following showed up in more than $50 \%$ of the samples: Ineffective health maintenance; Imbalanced nutrition - more than body requirements; Sedentary

lifestyle. Discussion: The findings show that these three diagnoses relate to a very important and unique issue in treating diabetic patients: the difficulty on the part of patients to adhere to treatment and self-care. Conclusion: The findings show that nursing diagnoses are useful with regard to identifying phenomena that require attention in specific treatment contexts, as well as acting as a guide in terms of the assistance offered.

Keywords: Nursing diagnosis; diabetes mellitus; nursing process. 


\section{INTRODUCTION}

Diabetes mellitus (DM) is a chronic disease with long-term results that may include degenerative, ophthalmologic and renal alterations, strokes, atherosclerosis and amputations $^{(1)}$. The high prevalence of this disease demonstrates the need for medical intervention to mitigate its development and complications.

A professional nurse, as an acting member of a multidisciplinary team, has a fundamentally educational role while monitoring patients with chronic diseases, such as diabetic patients. Several studies have shown the contributions made in terms of adherence to treatment and the identification of patients' problems which result from specific nursing intervention ${ }^{(2,3,4,5)}$. Nevertheless, if this intervention is to be proposed and can improve the quality of nursing assistance, it is essential to properly describe and identify these problems faced by patients.

The problems identified by a nurse throughout the nursing process can be termed Nursing Diagnoses (NDs). These guide choices in terms of individualized intervention with regard to diabetic patients and their families, and give the nurse full responsibility for the treatment and its results. However, in certain work contexts nurses still do not describe nursing phenomena as diagnoses, and thus do not use standardized terminology - which is a highly beneficial result of extensive research and development in this field.

This study aims to identify Taxonomy II Nursing Diagnoses as published by the North American Nursing Diagnosis Association International as used in diabetic outpatients' nursing records.

\section{METHOD}


This is an exploratory-descriptive and retrospective study. The research location was a school of nursing within a public hospital, with significant hospital and outpatient complexities, located in the city of Campinas, in the state of São Paulo, Brazil.

The data was obtained from the charts of 35 diabetic patients undergoing treatment at the General Adult Out Patients Department of this hospital, from May to August 2010, using data from the most recent nursing appointments. Medical charts from outpatients who quit treatment, had recovered or were deceased, were discarded. The first author of the study, who filled in a specific form for every medical chart, collected the data.

This data collection instrument consisted of three parts:

1) Socio-demographic characterization: patient's name, age, gender, date of birth, hospital registration number, marital status, occupation, family income and background.

2) Clinical characterization: represented by the main medical diagnosis, that is, DM1 (Diabetes Mellitus 1) or DM2 (Diabetes Mellitus 2), problems related to Systemic Arterial Hypertension (SAH), dyslipidemias, smoking, alcoholism, being overweight and obesity. For overweight the BMI was found to be greater than or equal to $25 \mathrm{Kg} / \mathrm{m}^{2}$ and for obesity, greater than or equal to $30 \mathrm{Kg} / \mathrm{m}^{2(6)}$. Blood glucose and glycated hemoglobin values were also used and respective values above $110 \mathrm{mg} / \mathrm{dL}$ and above $7 \%$ were considered a cause for concern ${ }^{(2)}$.

3) Nursing Diagnoses: considering those possible for the patients under consideration, this study used the Taxonomy II proposed by the North American Nursing Diagnosis Association International (NANDA-I), which is pre-eminent as a standardized classification for nursing terminology. It is also internationally renowned and available in several languages ${ }^{(7)}$.

This part of the instrument presented eight diagnoses proposed by NANDA-I ${ }^{(7)}$ and its components (risk factors, defining characteristics and related factors), based on the literature and medical experiments of the authors, which are: ineffective health maintenance; imbalanced nutrition - more than body requirements; inefficient 
peripheral tissue perfusion; Risk for lesion; risk of peripheral neurovascular dysfunction; Deficient knowledge; risk for unstable blood glucose level; sedentary lifestyle ${ }^{(7,8,9)}$.

As data were obtained, the diagnoses were highlighted according to the corresponding records that supported their proposition. To do so, the medical charts were analyzed by the first author - who had been trained to map out the problems and create the diagnoses proposition - and later discussed with the other researchers in meetings held every fortnight to reach a consensus on the diagnoses and their components.

The data was analyzed descriptively using absolute (n) and relative (\%) frequencies. The Research Ethics Committee of the Faculty of Medical Sciences at Campinas State University (Certified n434/2009) approved this research.

\section{RESULTS}

The medical charts of 35 diabetic patients were used in the research. The group was mainly made up of women (62.8\%; $n=22$ patients), of ages varying from 39 to 72 with an average of 54.6. Most of the patients are married $(65.7 \% ; n=23)$ and Caucasian $(88.6 \% ; n=31)$. As for occupation, $45.7 \%(n=16)$ are actively employed, $31.3 \%(n=11)$ are retired, $20 \%(n=7)$ work at home and 1 is unemployed $(2.8 \%) .27$ patients $(77.1 \%)$ have a fixed monthly income, and $22(62.8 \%)$ have an monthly income of between 300 USD and 1200 USD. 5 patients (14.2\%) have a monthly income of between 1500 USD and 2700 USD.

As for the educational background of the patients, data was unavailable for seven patients (20\%). Five others (14.2\%) are illiterate, but of these, two learned to read and write without formal education, as the records show. Consequently, of the 28 patients (80\%) who did have available data regarding education, the number of years of education varied from 0 to 15 , with an average of 7.75 . 
As far as clinical profiles are concerned, 32 patients (94.1\%) have DM 2; $29(82.9 \%)$ suffer from SAH; $23(65.7 \%)$ are obese, and $15(42.9 \%)$ have dyslipidemia. Only six patients (17.1\%) are smokers and $17(48.6 \%)$ have never smoked. As for alcohol abuse, $27(77.1 \%)$ have never had problems with alcoholism, 7 (20\%) had previous (but not current) problems, and only one $(2.8 \%)$ has problems with alcohol abuse at present.

Fasting glycemia varied between 89 to $330 \mathrm{mg} / \mathrm{dl}$, with an average of $161.3 \mathrm{mg} / \mathrm{dL}$. 21 (60\%) patients' glycemia was higher than $110 \mathrm{mg} / \mathrm{dL}$ and glycated hemoglobin affected over $7 \%$. On the other hand, the glycemia of $10(28.5 \%)$ patients was lower or equal to $110 \mathrm{mg} / \mathrm{dL}$. Glycated hemoglobin was lower or equal to 7\%. Four patient's medical charts had data on the results of these tests.

The following chart 1 shows the frequency of Nursing Diagnoses, according to the most recent patient consultation.

Chart 1 - Distribution of NANDA-I Nursing Diagnoses for 35 diabetic out-patients, Campinas, 2010.

\begin{tabular}{l|c|c}
\hline Nursing Diagnoses & $\begin{array}{c}\text { Patients } \\
\mathbf{N = 3 5}\end{array}$ & $\begin{array}{c}\text { Frequency } \\
\%\end{array}$ \\
\hline Ineffective health maintenance & 33 & 94,3 \\
Imbalanced nutrition - more than body requirements & 25 & 71,4 \\
Sedentary lifestyle & 23 & 65,7 \\
Risk for peripheral neurovascular dysfunction & 17 & 48,6 \\
Risk for unstable blood glucose level & 10 & 28,6 \\
Risk for lesion & 10 & 28,6 \\
Ineffective peripheral tissue perfusion & 8 & 22,9 \\
Deficient knowledge & 4 & 11,4 \\
\hline
\end{tabular}

Of the eight nursing diagnoses considered in this research, three aspects had the highest percentages in the patients' medical charts: Ineffective health maintenance $(n=33$; $94.3 \%)$; Imbalanced nutrition - more than body requirements $(n=25 ; 71.4 \%)$ and; sedentary lifestyle $(n=23 ; 65.7 \%)$. Chart 2 shows the nursing diagnoses with the description of their components. 
Table 2 - Actual nursing diagnoses for diabetic outpatients $(n=35)$. Campinas, 2010

\begin{tabular}{|c|c|c|}
\hline Actual diagnosis & Related factors and defining characteristics & $N$ \\
\hline $\begin{array}{l}\text { Ineffective health } \\
\text { maintenance } \\
33 \text { patient charts }\end{array}$ & $\begin{array}{l}\text { Related Factors } \\
\text { Lack of knowledge } \\
\text { Complexity of therapeutic regime } \\
\text { Excessive demands } \\
\text { Family habits/customs for healthcare } \\
\text { Financial difficulties } \\
\text { Defining characteristics } \\
\text { Daily routine choices that affect health goals } \\
\text { Failure to include treatment regimes in daily routines } \\
\text { Failure to act to reduce risk factors }\end{array}$ & $\begin{array}{c}27 \\
27 \\
20 \\
15 \\
5\end{array}$ \\
\hline $\begin{array}{l}\text { Imbalanced nutrition - } \\
\text { more than body } \\
\text { requirements } \\
25 \text { patient charts }\end{array}$ & $\begin{array}{l}\text { Related factors } \\
\text { Excessive intake in relation to metabolic needs } \\
\text { Defining characteristics } \\
\text { Overweight } \\
\text { Sedentary activity } \\
\text { Eating mainly at the end of the day } \\
\text { Compulsive eating }\end{array}$ & $\begin{array}{c}25 \\
23 \\
15 \\
5\end{array}$ \\
\hline $\begin{array}{l}\text { Sedentary lifestyle } \\
23 \text { prontuários }\end{array}$ & $\begin{array}{l}\text { Related Factors } \\
\text { Lack of interest } \\
\text { Lack of motivation } \\
\text { Lack of resources (time, money, company, means) } \\
\text { Lack of knowledge about the benefits of exercise } \\
\text { Defining characteristics } \\
\text { Lack of physical fitness } \\
\text { Daily routine without exercise }\end{array}$ & $\begin{array}{r}8 \\
4 \\
3 \\
\\
13 \\
20\end{array}$ \\
\hline
\end{tabular}

\section{DISCUSSION}

The findings were mainly present in women, but they do not point to a significant prevalence of diabetes in relation to gender, but rather an increase in frequency as age increases $^{(10)}$. 
Glycated hemoglobin is a much broader evaluation scope than fasting glycemia. Thus, this research shows that most of the patients had levels above $7 \%$, which implies the risk of hyperglycemic state complications in the long-run, such as neuropathy, kidney disease, retinopathy and cardiovascular events ${ }^{(10)}$. Furthermore, the sample shows important risk factors for additional complications with regard to diabetes, which should be a warning for the need for intervention proposals that improve treatment adherence.

All the proposed diagnoses for this research were identified in the patients' medical charts, with two to five diagnoses per patient: 17 patients (48.5\%) had three diagnoses. The three nursing diagnoses which are present in more than $50 \%$ of the patient charts are discussed below:

The nursing diagnosis Ineffective health maintenanceis defined as an unsatisfactory standard of regulation and integration to the daily routine of a therapeutic regime for the treatment of diseases and their sequelae to reach specific health goals.Imbalanced nutrition - more than body requirementsis defined as the ingestion of nutrients that exceeds metabolic necessities. The third diagnosis is Sedentary lifestyle, which "refers to a daily routine with little physical activity"(7).

These events so well described by standardized nursing terminology corroborate the literature on diabetic patients ${ }^{(3,11,12)}$. Thus, nursing diagnoses are extremely useful for describing phenomena that require attention and which, once identified, the nurse accepts full responsibility for. They also guide intervention, making communication and documentation more efficient.

These three nursing diagnoses and their components (defining characteristics and related factors) are considered to be related to common problems in a diabetic patient context: problems of adhering to treatment and managing self-care. Self-care for diabetics can be defined as a set of tasks that the patient must be committed to undertake in order to be healthy. This includes the ability, knowledge and confidence to make daily decisions, 
select and change behavior, besides dealing with the emotional aspects of the disease in the context of daily living ${ }^{(3)}$. The intensity and daily repetition of the treatment - often draining and difficult - has a significant impact on the patient's life and family. Thus, an early nursing diagnosis can help a nurse propose interventions that help change a patient's attitude.

A low level of adherence to treatment is a complex problem facing patients with chronic disease. The obstacles to adherence are irrespective of the system in which the patient is inserted $^{(13)}$. It is important to highlight that responsibility for one's own health is not negotiable, and cannot be transferred to others or sidelined. Although known for years, the dilemma remains regarding methods to improve self-care and adherence to the proposed treatment. Several strategies have been developed, evaluated and implemented in an effort to solve this problem $^{(3,14)}$. The most significant results were seen when these strategies were associated (education of the patient, patient's family and health professionals), patients participated in the decisions regarding their treatment, and when meetings between patients and nurses were relatively frequent and over a longer period. What still seems to be lacking is randomized research that monitors the long-term outcomes ${ }^{(14)}$.

From a clinical point of view, the nursing diagnoses found in this research indicate the treatment needs that must be prioritized, and which frequently overlap, as shown in the literature ${ }^{(3,11,12)}$. This also shows the clinical usefulness of standardized nursing terminology, as it is capable of describing the human response which requires attention and intervention to support it scientifically. Nevertheless, at times, nurses do not recognize and use this important tool.

\section{CONCLUSION}

The nursing phenomena that stood out the most in this sample taken from patient medical charts were: Ineffective health maintenance; Imbalanced nutrition - more than 
body requirements and; a sedentary lifestyle. As a large part of diabetes management (aside from medication treatment) is based on patient self-care, the nursing diagnoses mentioned here adequately describe the human responses shown by these patients.

Naming problems as a result of nursing diagnoses allows for the identification of nursing interventions aimed towards the actual needs of these patients, which enables the development of individualized and efficient treatment. It also improves communication among health workers and treatment registration.

This research was limited by patient charts that did not have standardized nursing terminology and by succinct records that lacked sufficient data to offer more insights into defining characteristics, related factors or risk factors that could assist in medical analysis. Therefore, this research can contribute to highlighting the importance for nurses to appropriate diagnostic skills and the accurate use of nursing terminology.

\section{REFERENCES}

1.International Diabetes Federation [ homepage on the internet ]. Epidemiology and morbidity [ cited 2011 Mar 01 ] . Available from: http://www.idf.org/

2.Stewart GL, Tambascia M, Guzmán JR, Etchegoyen F, Carrión JO, Artemenko S. Control of type 2 diabetes among general practitioners in private practice in nine countries of Latin America. Rev Panam Salud Publica. 2007; 22(1): 12-20.

3.Funnell MM, Anderson RM. Changing office practice and healthcare systems to facilitate diabetes self-management. Curr Diab Rep. 2003; 3(2): 127-33.

4.Gillibrand W, Holdich P, Covill C. Managing type 2 diabetes: new policy and interventions. $\mathrm{Br}$ J Community Nurs. 2009; 14(7):288-91.

5.Teston E.Marques F.Marcon S. Diagnoses and nursing actions for individuals with chronic diseases assisted at home: descriptive study. Online Brazilian Journal of Nursing 
[ serial on the Internet ]. 2010 December 18 [ Cited 2012 April 20 ] 9(3). Available from: http://www.objnursing.uff.br/index.php/nursing/article/view/3059

6.World Health Organization - WHO [ homepage on the internet ]. Obesity and overweight [ cited 2012 Feb 10 ]. Available from: http://www.who.int/mediacentre/ factsheets/fs311/en/index.html

7.North American Nursing Diagnoses Association - International. Diagnósticos de Enfermagem da NANDA-I: definições e classificação, 2009-2011. Porto Alegre: Artmed; 2010.

8.Müller-Staub M. Evaluation of the implementation of Nursing Diagnoses, Interventions, and Outcomes. Int J Nurs Terminol Classific. 2009; 20(1):9-15

9.Teixeira CRS, Zannetti ML, Pereira MC. Nursing diagnoses in people with diabetes mellitus according to Orem's theory of selfcare. Acta Paul Enferm. 2009; 22(4): 385-91.

10.Carolino IDR, Molena-Fernandes CA, Tasca RS, Marcon SS, Cuman RKN. Fatores de risco em pacientes com diabetes mellitus tipo 2. Revista Latino-am Enferm. 2008; 16 (2): $238-44$.

11. Minet LKR, Wagner L, Lonving EM, Hjelmborg J, Henriksen JE. The effect of motivational interviewing on glycaemic control and perceived competence of diabetes self-management in patients with type 1 and type 2 diabetes mellitus after attending a group education programme: a randomized controlled trial. Diabetologia. $2011 ; 54(7)$ : 1620-9.

12. Carter D, Capehorn M. Weight management of obese people with diabetes. J Diabetes Nurs. $2011 ; 15(1): 6-8$.

13. Nama S, Chesla C, Stotts NA, Kroon L, Janson SL. Barriers to diabetes management: patient and provider factors. Diabetes Res Clin Pract. $2011 ; 3(1): 1-9$. 
14.Rygg LO, Rise MB, Gronning K, Steinsbekk A. Efficacy of ongoing group based diabetes self-managemente education for patients with type 2 diabetes mellitus: a randomized controlled trial. Patient Educ Couns. 2012 Jan; 86 (1):98-105.

15.Lerman I, López-Ponce A, Villa AR, Escobedo M, Caballero EA, Velasco ML, GómezPérez FJ, Rull-Rodrigo JA. Pilot study of two different strategies to reinforce self care behaviors and treatment compliance among type 2 diabetes patients from low income strata. Gac Med Mex. 2009; 145(1): 15-9.

Received: $22 / 04 / 2012$

Approved: $31 / 01 / 2013$

\section{Participation of authors in the research}

Lillian Helena Alves da Silva: study design, literature review, data collection, drafting tables, data analysis, final report of the research.

Elenice Valentim Carmona: study design, data analysis, critical revision of article, final approval of the article.

Ana Raquel Medeiros Beck: data analysis, critical revision of article, final approval of the article.

Maria Helena Melo Lima: study design, data analysis, critical revision of article, final approval of the article.

Eliana Pereira de Araújo: conception and study design, data collection, data analysis, critical revision of article, final approval of the article. 